\title{
Factors influencing the quality of postoperative epidural analgesia: an observational multicenter study
}

This article was published in the following Dove Press journal:

Local and Regional Anesthesia

5 August 2014

Number of times this article has been viewed

\author{
Piotr Wranicz' \\ Hege Andersen' \\ Arve Nordbø' \\ Ulf E Kongsgaard ${ }^{1,2}$ \\ 'Department of Anaesthesiology, \\ Division of Emergencies and Critical \\ Care, Oslo University Hospital, \\ Oslo, Norway; ${ }^{2}$ Medical Faculty, \\ Oslo University, Oslo, Norway
}

\begin{abstract}
Background: Epidural analgesia (EDA) is used widely for postoperative pain treatment. However, studies have reported a failure rate of EDA of up to $30 \%$. We aimed to evaluate the quality of postoperative EDA in patients undergoing a laparotomy in five Norwegian hospitals.

Methods: This was a multicenter observational study in patients undergoing a laparotomy with epidural-based postoperative analgesia. Data were registered at three time points. Technical aspects, infusion rates, pain intensity, assessment procedures, side effects, and satisfaction of patients and health personnel were recorded. The use of other pain medications and coanalgesics was registered.

Results: Three hundred and seventeen patients were included. Pain control at rest was satisfactory in $89 \%$ of patients at 24 hours and in $91 \%$ at 48 hours. Pain control when coughing was satisfactory in $62 \%$ at 24 hours and in $59 \%$ at 48 hours. The spread of hypoesthesia was consistent for each individual patient but varied between patients. The hypoesthetic area was not associated with pain intensity, and the precision of the EDA insertion point was not associated with the pain score. Few side effects were reported. EDA was regarded as effective and functioning well by $64 \%$ of health personnel.

Conclusion: EDA was an effective method for postoperative pain relief at rest but did not give sufficient pain relief during mobilization. The use of cold stimulation to assess the spread of EDA had limited value as a clinical indicator of the efficacy of postoperative pain control. Validated tools for the control of EDA quality are needed.
\end{abstract}

Keywords: epidural, pain, analgesia, postoperative, quality

\section{Introduction}

Epidural analgesia (EDA) is superior to systemic opioids, according to major systematic reviews. ${ }^{1-4}$ However, clinical practice shows that many patients experience pain during mobilization, physiotherapy, and coughing, despite receiving efficient pain relief at rest. Recent comprehensive studies suggest that earlier trials of postoperative pain used inadequate methods to assess movement-evoked pain: ie, five of seven meta-analyses did not distinguish between pain at rest and pain during mobilization. ${ }^{5,6}$ Sensory testing using cold stimulation is an established method for quality control of postoperative EDA in several hospitals, although this routine procedure has never been properly validated. A failure rate of up to $30 \%$ has been reported in previous studies. ${ }^{?}$

\section{Aim of the study}

The main purpose of the study was to evaluate the quality of EDA in patients undergoing a midline longitudinal laparotomy. The secondary aims were to analyze the 
effectiveness of EDA as a method specifically for control of pain evoked by movement and to explore the relationship between sensory changes in the skin (hypoesthesia) and quality of the EDA block. We also wanted to determine the surgery department's nursing staff's satisfaction with the quality of pain control with EDA.

\section{Methods}

In response to our application, the Regional Committees for Medical and Health Research Ethics (South East) informed us that approval was not necessary because the study was categorized as quality control of established medical treatment (REK no S-09152d, dated March 3, 2009). The study was approved by the hospitals' research boards and the Norwegian Social Science Data Services.

This was a multicenter observational study conducted in five Norwegian hospitals from April 2009 to December 2010 (Table 1). The inclusion criteria were patients undergoing a laparotomy with an epidural-based postoperative analgesia and age $>18$ years. They had to be cognitively competent, and written informed consent was obtained for all patients. The type of surgery and miscellaneous demographic data were registered.

We registered data in a timeline from the anesthetist's plan for performing the technique, through monitoring the effect of the pain treatment 24 hours and 48 hours postoperatively. Patients indicated their degree of satisfaction at the end of the observation period (Figure 1).

Pain intensity (used as a surrogate for EDA efficacy) was measured with an eleven-point numeric rating scale (NRS) at

Table I Demographic data

\begin{tabular}{lll}
\hline & & Missing \\
\hline $\begin{array}{l}\text { Age, years (median + quartiles) } \\
\text { Sex (number) }\end{array}$ & $63(54,70)$ & 4 \\
$\quad$ Male & 148 & 3 \\
Female & 158 & 10 \\
Height, cm (median + quartiles) & $170(164,180)$ & 5 \\
Weight, kg (median + quartiles) & $73(64,85)$ & 0 \\
Patients included from each & & \\
hospital (number) & & \\
Norwegian Radium Hospital & 101 & \\
National University Hospital & 75 & 0 \\
Ullevål University Hospital & 58 & \\
Fredrikstad Central Hospital & 21 & \\
Tønsberg Central Hospital & 54 & \\
Type of surgery (number) & & \\
Gastrointestinal surgery & 215 & \\
Gynecological surgery & 40 & \\
Urological surgery & 29 & \\
Vascular surgery & 14 & \\
Others & 11 & \\
\hline
\end{tabular}

two time points: 24 hours and 48 hours postoperatively. At 24 hours, the score on the NRS was registered at rest and after coughing. At 48 hours, the NRS score was registered at rest, after coughing, and under mobilization (standing bedside). Good pain control was defined as a rating of $\leq 3$ at rest and $\leq 4$ under provocation (ie, coughing and/or mobilization). ${ }^{8,9}$ The need for rescue medication and adjuvant analgesics was recorded.

To analyze the effectiveness of EDA as a tool for the control of breakthrough pain and to measure pain intensity (NRS) under provocation (coughing and mobilization), we used the NRS limits described and explored further the data from patients with an NRS score $\geq 5$ at both time points.

Epidural insertion was performed using a median or paramedian approach. The approach, the level of insertion (actual dermatome), and the calculated length of the epidural catheter in the epidural space were recorded. The anesthetist's experience (years in the profession) was included. The length of the surgical incision (the highest and lowest dermatomes) was noted, and the difference between the insertion point of the epidural needle and the midpoint of the surgical wound was calculated (hereinafter called "EDA precision"). The relationships between EDA precision and all the NRS scores at the different time points were evaluated.

The EDA infusion rates were monitored. The difference between the maximum prescribed infusion rate and the actual given rate was calculated and was then analyzed in relation to the NRS scores. We also asked the doctors and nurses to describe any reasons for reducing the epidural infusion rate or stopping the EDA. The use of other pain medications and coanalgesics in addition to EDA was registered.

Evaluation of the bedside sensory test (cold stimulation test) used for quality control of EDA was conducted as follows. Both sides of the thoracic and abdominal walls were examined. An ice cube inside a rubber glove was placed on the patient's skin and moved (with continuous contact) from dermatome T4-5 to L5-S1. Any reduction in cold perception was recorded as the relevant dermatome level. Failure to perceive the temperature change or a complete lack of temperature sensation was also recorded.

Hypoesthesia evaluated by the cold stimulation test was examined on the right and left sides of the abdomen and was classified into one of the following four categories: 1) good coverage (reduced skin sensitivity over the region of the surgical wound), 2) partial coverage (uncertain or patchy reduced skin sensitivity over the region of the surgical wound), 3) disjointed coverage (reduced skin sensitivity over 


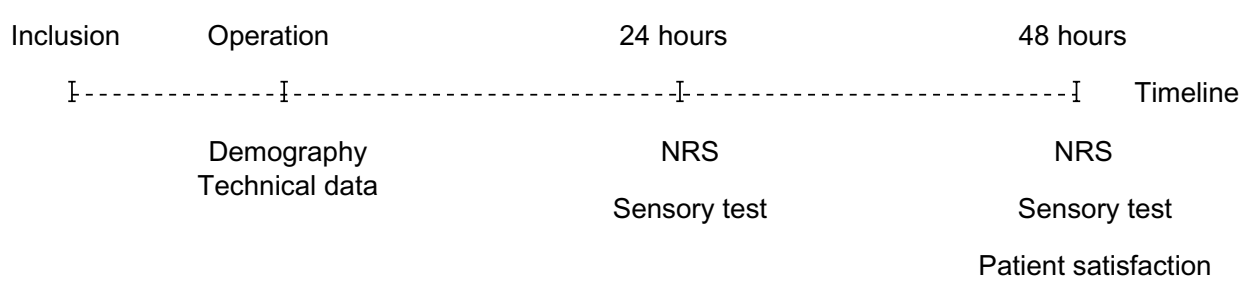

Figure I Registered data in a timeline from the anesthetist's plan for performing the technique, through monitoring the effect of the pain treatment 24 hours and 48 hours postoperatively.

Abbreviation: NRS, numeric rating scale.

a region other than the surgical incision), and 4) no coverage (no apparent region of reduced skin sensitivity).

The participating study investigators evaluated the effectiveness of the EDA at 48 hours by assessing the overall success, side effects, and problems. We asked the nurses to record any side effects such as itching, nausea, and hypotension or reduced muscle power. The nurses were also asked about their education and understanding of, EDA and their ability to monitor the patients. The nurses' and the patients' overall satisfaction with the EDA method was recorded.

\section{Statistical methods}

Descriptive statistics were used to present the demographic and clinical characteristics of the patients. The descriptive statistics were presented as medians and quartiles if not stated otherwise. The associations between the epidural infusion rate and pain intensity, and between the infusion difference (maximum prescribed infusion rate minus actual given infusion rate) and pain intensity were analyzed using Pearson product-moment correlation. A possible association between the EDA precision and the NRS scores at different time points was also analyzed with Pearson product-moment correlation. A one-way between-groups analysis of variance was conducted to explore the effects of EDA coverage (where coverage was equal on each side of the abdomen) on the sum NRS score at 24 hours and 48 hours. Tests were two-tailed and $P<0.05$ was considered significant. All analyses were performed using PASW Statistics 18 (SPSS Inc., Chicago, IL, USA).

\section{Results}

We included 317 patients in the study. There were eight dropouts: five patients because of incomplete data, two because of postoperative complications, and one who did not receive the EDA as planned. The demographic data are presented in Table 1. Good pain control at rest was obtained in $89 \%$ of patients at 24 hours and in $91 \%$ at 48 hours. Good pain control when coughing was obtained in $62 \%$ at 24 hours and in $59 \%$ at 48 hours. The ratings of pain measured at 24 hours and at 48 hours are presented in Table 2.

The epidural catheters were inserted by experienced anesthetists. The technical aspects of the epidural catheters and surgical incisions are presented in Table 2. Most catheters were inserted in the lower thoracic region (Table 3). Four catheters were inserted above $\mathrm{T} 7$ and 18 catheters were inserted below T12. Most catheters were inserted 5-7 $\mathrm{cm}$ into the epidural space; however, the catheter was inserted $<3.5 \mathrm{~cm}$ in 12 patients and $>8.5 \mathrm{~cm}$ in 23 patients. Most patients had surgical incisions that covered 4.5 to six dermatomes (Table 3 ), but 23 patients had a surgical incision that covered three or fewer dermatomes. The EDA precision and NRS scores did not correlate significantly at any time points.

The prescribed epidural infusion rates and the actual given infusion rates are shown in Table 4. Infusion rates were significantly higher for the patients with higher NRS scores. The difference between the maximum prescribed infusion rate and the actual given infusion rate (infusion rate discrepancy) did not correlate significantly with pain scores. In $>40 \%$ of the patients, the epidural infusion rate was unchanged during the first 48 hours postoperatively. The reasons given for reducing the EDA infusion rate or withdrawing the treatment were decreased pain in $22 \%$ and unsatisfactory pain relief from this method in $14 \%$ of the

Table 2 Pain intensity 24 hours and 48 hours after surgery

\begin{tabular}{llll}
\hline & $\begin{array}{l}\text { Median } \\
\text { (quartiles) }\end{array}$ & $\begin{array}{l}\text { Satisfaction } \\
\text { (\%) }\end{array}$ & Missing \\
\hline NRS at rest at 24 hours & I $(0,2)$ & $269(89)$ & 6 \\
$\begin{array}{l}\text { NRS with coughing at } \\
24 \text { hours }^{\mathrm{a}}\end{array}$ & $4(2,5)$ & $186(62)$ & 9 \\
$\begin{array}{l}\text { NRS at rest at 48 hours } \\
\text { NRS with coughing at }\end{array}$ & $\mathrm{I}(0,2)$ & $272(91)$ & $1 \mathrm{I}$ \\
48 hours $^{\mathrm{a}}$ & $4(2,5)$ & $173(59)$ & 15 \\
$\begin{array}{l}\text { NRS during mobilization } \\
\text { at 48 hours }\end{array}$ & $3(2,5)$ & $189(66)$ & 22 \\
\hline
\end{tabular}

Notes: aNumeric rating scale score (NRS) (eleven-point scale from 0 indicating no pain to 10 indicating worst pain). Satisfaction: good pain control, defined as $\leq 3$ at rest and $\leq 4$ under provocation (coughing and mobilization). 
Table 3 Technical aspects of epidural catheters and surgical incisions

\begin{tabular}{lll}
\hline $\begin{array}{l}\text { Insertion level } \\
\text { (median + quartiles) }\end{array}$ & $\begin{array}{l}\text { T9-10 } \\
\text { (T8-9, T I0-I I) }\end{array}$ & Missing \\
\hline $\begin{array}{l}\text { Distance to LOR, cm } \\
\text { (median + quartiles) }\end{array}$ & $6(2$, II) & Missing: I I \\
$\begin{array}{l}\text { Calculated intraepidural length } \\
\text { of catheter, cm (median + quartiles) }\end{array}$ & $6(5,7)$ & Missing: I5 \\
$\begin{array}{l}\text { Insertion approach (number) } \\
\quad \text { Median }\end{array}$ & 21 II & Missing: 32 \\
$\quad$ Paramedian & 66 & Missing: 0 \\
$\begin{array}{l}\text { Standard epidural solution, }{ }^{a} \\
\text { \% of patients }\end{array}$ & 98.4 & Missing: 19 \\
$\begin{array}{l}\text { Length of surgical incisions, number } \\
\text { of dermatomes (median + quartiles) }\end{array}$ & $5(4.5,6)$ & \\
\hline
\end{tabular}

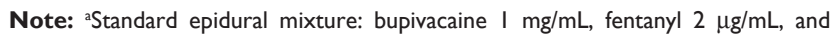
adrenalin $2 \mu \mathrm{g} / \mathrm{mL}$ in $98.4 \%$ of patients.

Abbreviations: LOR, loss of resistance; T, thoracic vertebra.

309 patients assessed. In $12 \%$ of patients, no reason was given for the decision by the attending surgeon to wean the patient off the EDA.

The catheter position was adjusted by limited withdrawal within 48 hours postoperatively in $16 \%$ of the patients, and another $6 \%$ received a new epidural catheter at some point. An opioid (ketobemidone) was given intravenously to $44.4 \%$ of the 309 patients during the first 24 hours and to $30.5 \%$ during the next 24 hours. Oral oxycodone was given to $16.1 \%$ of the patients during the first 24 hours and $28 \%$ during the next 24 hours. Paracetamol was given to $90.0 \%$ and nonsteroidal analgesics to $8.7 \%$ of the patients in the postoperative period.

The hypoesthesia distributions on the left and right sides of the body at both measurement points were fairly consistent for individual patients; however, there was considerable variability between patients (Table 5). In 16\% of the sensory tests (average of two tests at two time points), no hypoesthetic area was registered. There were no clear relationships between

Table 4 Infusion rates of the epidural mixture

\begin{tabular}{|c|c|c|}
\hline & $\begin{array}{l}\text { Median } \\
\text { (quartiles) }\end{array}$ & Missing \\
\hline Prescribed maximum infusion rate $(\mathrm{mL} / \mathrm{h})$ & $14(12,15)$ & 3 \\
\hline Prescribed bolus (mL) & $4.5(2,5)$ & 23 \\
\hline Infusion rate at 24 hours $(\mathrm{mL} / \mathrm{h})$ & $8(6,10)$ & 2 \\
\hline Infusion rate at 48 hours $(\mathrm{mL} / \mathrm{h})$ & $8(6,10)$ & 14 \\
\hline $\begin{array}{l}\text { Difference between prescribed maximum } \\
\text { infusion and actual infusion given at } \\
24 \text { hours }(\mathrm{mL} / \mathrm{h})\end{array}$ & $5(2,7)$ & 5 \\
\hline $\begin{array}{l}\text { Difference between prescribed maximum } \\
\text { infusion and actual infusion given at } \\
48 \text { hours }(\mathrm{mL} / \mathrm{h})\end{array}$ & $5(2,8)$ & 17 \\
\hline
\end{tabular}

Table 5 Results of the cold stimulation test at 24 hours and 48 hours after surgery ${ }^{\mathrm{a}}$

\begin{tabular}{|c|c|c|c|c|}
\hline & $\begin{array}{l}\text { Right side } \\
24 \text { hours }\end{array}$ & $\begin{array}{l}\text { Left side } \\
24 \text { hours }\end{array}$ & $\begin{array}{l}\text { Right side } \\
48 \text { hours }\end{array}$ & $\begin{array}{l}\text { Left side } \\
48 \text { hours }\end{array}$ \\
\hline Good coverage & 20 & 14 & 9 & 12 \\
\hline Partial coverage & 142 & 135 & 122 & 116 \\
\hline $\begin{array}{l}\text { Disjointed } \\
\text { coverage }\end{array}$ & 88 & 87 & 90 & 90 \\
\hline No coverage & 28 & 43 & 52 & 54 \\
\hline $\begin{array}{l}\text { Total number } \\
\text { of patients }\end{array}$ & 278 & 279 & 273 & 272 \\
\hline
\end{tabular}

Notes: ${ }^{2}$ The data are expressed as number of patients. Good coverage: reduced skin sensitivity over the region of the surgical wound, partial coverage: uncertain or patchy reduced skin sensitivity over the region of the surgical wound, disjointed coverage: reduced skin sensitivity over regions other than the surgical incision, and no coverage: no apparent region of reduced skin sensitivity.

EDA coverage (where coverage was equal on each side of the abdomen) and the sum of NRS scores at 24 hours and 48 hours. The EDA was regarded as effective and functioning well by $64 \%$ of health personnel on the ward. Some unilateral effects were noted in 38 patients, patchy effects in 27 patients, incomplete effects in 25 patients, and possible wrong anatomical regional in 24 patients (Table 6).

We recorded side effects in 43 of the 309 patients (13.9\%). The most frequent side effect was itching in $7.4 \%$, followed by nausea in $5.2 \%$, sedation in $3.5 \%$, and reduced muscle strength in $2.6 \%$ of the patients. Responses from questionnaires demonstrated that EDA in these patients was regarded as satisfactory by nurses as well as by patients (Table 6).

\section{Discussion}

EDA is used widely in Norwegian hospitals, often after abdominal surgery with a midline incision or after thoracic surgery. ${ }^{10}$ In the five participating hospitals, EDA is usually administered as patient-controlled epidural analgesia (PCEA): continuous infusion + bolus dose. The most common drug combination in epidural solutions used in Norway, including in the five participating hospitals, is fentanyl $2 \mu \mathrm{g} / \mathrm{mL}$, bupivacaine $1 \mathrm{mg} / \mathrm{mL}$, and adrenaline $2 \mu \mathrm{g} / \mathrm{mL}$.

Table 6 Nurses' and patients' satisfaction with epidural analgesia (EDA) measured with an eleven-point NRS scale ${ }^{a}$

\begin{tabular}{lll}
\hline & Median (quartiles) & Missing \\
\hline $\begin{array}{l}\text { Nurses' overall satisfaction } \\
\text { with EDA (median + quartiles) }\end{array}$ & $8(7,9)$ & 9 \\
$\begin{array}{l}\text { Nurses' satisfaction with EDA } \\
\text { educational level }\end{array}$ & $8(7,9)$ & 9 \\
Patients' satisfaction with EDA & $8(7,10)$ & 20 \\
\hline
\end{tabular}

Notes: aResponses to questionnaires from 309 patients. Numeric rating scale (NRS) score (eleven-point scale where 0 represents very dissatisfied and 10 very satisfied). 
Clinical observation has shown that satisfactory pain control (NRS $\leq 3$ ) can be achieved in the recovery room, although some patients experience frequent episodes of intense pain in the surgical ward. ${ }^{10}$ Unsatisfactory pain treatment in this patient group is caused by multiple factors. In our opinion, the most important reason is breakthrough pain provoked by mobilization, physiotherapy, deep respiration, and/or coughing. Breakthrough pain is an acknowledged problem during the postoperative phase. ${ }^{5}$ Early mobilization and effective lung physiotherapy demand sufficient control of pain aggravation. Unfortunately, there is limited awareness of the distinction between pain measured at rest and movement-related pain. ${ }^{3}$ Forty percent of clinical postsurgical EDA trials did not distinguish between these two types of pain. ${ }^{5,6}$ Acute pain should be assessed during movement. This is essential for regaining physical function and for avoiding the risk of postoperative complications. ${ }^{11}$ This may cause methodological problems for evaluating outcomes in pain research. In our study we found differences between pain at rest and evoked pain. Eleven percent of patients had insufficient pain relief at rest ( 24 hours) with NRS $>3$, which may seem to be an acceptable rate for EDA; however, the rate was nearly four times higher for movement-evoked pain, which is a disappointing result. The data collected at 48 hours showed a similar outcome with an even more marked difference between pain after coughing and mobilization.

Not surprisingly, EDA infusion rates were higher for the patients with more pain. Although the infusion rate in many patients was not increased up to the maximum dose prescribed, we cannot conclude that more patients would have had an acceptable pain level, given that there was no correlation between pain intensity and the infusion rate discrepancy (difference between maximum prescribed infusion and actual given dose).

Earlier studies have shown a superior effect of PCEA over the intravenous patient-controlled analgesia strategy for moderate and severe pain. ${ }^{1,2}$ However, this is not necessarily true for exacerbation of pain during provocation. PCEA may be beneficial for pain control because the bolus doses are given by the patient. Considering the slow onset time of epidural blocks (15-20 minutes for bupivacaine), however, our results indicating poor pain control of breakthrough pain are not surprising. Moreover, a recent study analyzing movement-evoked breakthrough cancer pain treated with continuous intrathecal analgesia showed poor pain control for transitory exacerbation of pain. ${ }^{12}$ Two earlier Cochrane reports demonstrated a superior effect of EDA for movementevoked pain in postoperative patients. ${ }^{1,2}$ However, we did not find similar benefits in our study, possibly because of insufficient instruction and poor understanding of the function of controlled analgesia as rescue medication among our patients.

Insufficient analgesia associated with indwelling epidural catheters (malposition, migration, kink, dislodgment) is also an important reason for poor pain relief. ${ }^{13}$ The segmental level for the tip of the epidural catheter should ideally be located in a place where infusion of the epidural mixture should cover the dermatomes of the surgical incision. It is somewhat disappointing that we found no relationship between the EDA precision (relating to the midpoint of the surgical wound) and NRS scores at any time points. However, a number of variables can affect the position of the tip relative to the insertion point. ${ }^{14,15}$ Two studies have confirmed that the position of the catheter tip can be unpredictable if the insertion is $>5 \mathrm{~cm}$ into the epidural space, although one study reported a higher success rate with an insertion $>5 \mathrm{~cm} \cdot{ }^{16-18}$ In our data the median length of $6 \mathrm{~cm}$ may have been one reason for the unsatisfactory catheter position and incomplete spread of EDA infusion. Although $6 \mathrm{~cm}$ is not considerably more than what is recommended, we note that in 23 of our patients the catheter was inserted $>8.5 \mathrm{~cm}$ into the epidural space. However, our study was not designed to analyze this phenomenon specifically.

The epidural catheter insertion level and length in the epidural space are two important factors influencing the optimal distribution of the epidural drug solution and should be the result of a deliberate preoperative decision. Unsatisfactory pain treatment with EDA should be defined and documented as soon as possible. The reasons for a poor effect should be examined before the patient is discharged from the recovery room. ${ }^{19}$ The patient's compliance with, and understanding of, the PCEA bolus function are also important and probably are underestimated as factors affecting epidural sufficiency. We did not examine these factors in our study.

Testing of skin hypoesthesia around the surgical incision is a common method for monitoring the distribution of the epidural infusion in many countries. To differentiate the anesthetized skin area we used the cold stimulation test (skin stimulation with an ice cube) in all the hospitals included in the study. This bedside test is usually administered and documented by nursing personnel. The results are assumed to be relevant to the need for adjustment of the epidural infusion rate. However, several factors can influence the final result of the skin test, such as the patient's understanding of the test and perception of low temperature, the examination method used by nurses, and the concentration of local anesthetics. In addition, the distribution of sensitivity does not follow a 
definite pattern and can be asymmetrical, one-sided, patchy, or absent, even when postoperative pain relief is satisfactory. Some patients receive simultaneous systemic analgesia, which can affect the NRS score. This occurred in our study and was evident as a noticeable discrepancy between postoperative EDA quality and sensory test. Thus, we conclude that the sensory test has low specificity and poor predictive value for estimating pain control. This is consistent with a study by Curatolo et al, ${ }^{20}$ who found that the spread and efficacy of EDA as assessed by pinprick and cold tests correlated poorly with the intensity of postoperative pain.

For how long do patients need postoperative EDA? The answer is complex and depends on a number of factors: the type and extent of surgery, the patient's pain threshold, comorbidity, local practices, and logistics. In our group of patients, $22 \%$ of the catheters were removed by 48 hours because of the perception of low pain intensity, and 14\% were removed because of unsatisfactory pain relief. Clinicians working in the surgical ward sometimes misinterpret the perception that EDA is insufficient. Instead of demanding an increment in EDA infusion, some clinicians probably discontinue EDA too early. In our study, $12 \%$ of the patients received a reduced infusion rate according to the surgeon's preference but with no reasons given. We speculate that there is a general tendency for reduced "epidural time" postoperatively and possible early use of oral analgesics to shorten the hospital stay.

The patients included in the study were very satisfied with the EDA technique. However, this information alone has limited value considering that different options are available for postoperative analgesic control and patients have no basis for comparison. If other techniques had been used and compared with EDA, perhaps the results would have been different.

The quality of postoperative EDA in patients undergoing a laparotomy is influenced by a number of factors. In this heterogeneous patient group it is difficult to identify which specific factor is the most important for success. The term "quality" is challenging by itself. Efficacy variables other than pain intensity, such as the time to bowel movement, number of hospital days, and persistent postoperative pain, are also important but were not investigated in this study. Although EDA for postoperative pain works well in many anesthetists' experience, it is claimed that epidural failure is a frequent clinical problem. ${ }^{14}$ However, there is no clear definition of the term "failed epidural", which covers a wide spectrum of outcome measures. We speculate that some of the so-called failed epidurals reported are EDAs that could have been improved by better follow-up by an acute pain service that supervises and implements educational programs for all personnel involved in the care of surgical patients. ${ }^{21}$

This study has some limitations. When using EDA specifically for control of breakthrough pain, one should consider that correct use of the EDA bolus doses demands prediction of incident pain, for example, before intended movement. This was not examined in our study. On the other hand, spontaneous coughing cannot be controlled sufficiently by this method. Exploring the relationship between sensory changes in the skin (hypoesthesia) and quality of the EDA block has several limitations. In addition to the subjective nature of the bedside test, anesthesia-related impaired cognitive function can bias a patient's perception and evaluation of cold stimulation of the skin. Our patients received simultaneous systemic analgesia as needed. It can be difficult to interpret the balance between additional systemic analgesics and the possibility of adjusting the EDA infusion to improve analgesia. Furthermore, closer guidance from an acute pain team in surgeons' and nurses' adjustments of the epidural infusion rates could have been an advantage.

\section{Conclusion}

EDA with fentanyl $2 \mu \mathrm{g} / \mathrm{mL}$, bupivacaine $1 \mathrm{mg} / \mathrm{mL}$, and adrenaline $2 \mu \mathrm{g} / \mathrm{mL}$ is an effective method for postoperative pain control for patients at rest after laparotomy but is not sufficiently effective for treating dynamic pain (ie, movement related). The method may be unsatisfactory for patients who need a quick, spontaneous change in analgesia level: eg, during coughing. The patient's understanding of the self-controlled function of the infusion pump is essential. The 15 to 20-minute onset time for a rescue dose of local anesthetics should be included in the correct use of the PCEA method. Validated tools for control of EDA quality are still lacking. Testing the spread of the local anesthetic effect on the patient's skin with cold stimulation and mapping hypoesthesia in the operated area have low specificity and low predictive value for determining the quality of analgesia.

\section{Acknowledgments}

This study was supported by departmental funding only. The authors are grateful to Leiv Arne Rosseland, Luis Romundstad, and Audun Stubhaug for constructive comments after reviewing the manuscript.

\section{Disclosure}

The authors report no conflicts of interest in this work. The authors alone are responsible for the content and writing of the paper. 


\section{References}

1. Nishimori M, Ballantyne JC, Low JH. Epidural pain relief versus systemic opioid-based pain relief for abdominal aortic surgery. Cochrane Database Syst Rev. 2006(3):CD005059.

2. Werawatganon T, Charuluxanun S. Patient controlled intravenous opioid analgesia versus continuous epidural analgesia for pain after intra-abdominal surgery. Cochrane Database Syst Rev. 2005(1):CD004088.

3. Hudcova J, McNicol E, Quah C, Lau J, Carr DB. Patient controlled opioid analgesia versus conventional opioid analgesia for postoperative pain. Cochrane Database Syst Rev. 2006(4):CD003348.

4. Mann C, Pouzeratte Y, Boccara G, et al. Comparison of intravenous or epidural patient-controlled analgesia in the elderly after major abdominal surgery. Anesthesiology. 2000;92(2):433-441.

5. Srikandarajah S, Gilron I. Systematic review of movement-evoked pain versus pain at rest in postsurgical clinical trials and meta-analyses: a fundamental distinction requiring standardized measurement. Pain. 2011;152(8):1734-1739.

6. Parker P. Systematic review of movement-evoked pain versus pain at rest in postsurgical clinical trials and meta-analyses: a fundamental distinction requiring standardized measurement. Pain. 2012;153(1):250.

7. Ready LB. Acute pain: lessons learned from 25,000 patients. Reg Anesth Pain Med. 1999;24(6):499-505.

8. Andersen LO, Gaarn-Larsen L, Kristensen BB, Husted H, Otte KS, Kehlet H. Subacute pain and function after fast-track hip and knee arthroplasty. Anaesthesia. 2009;64(5):508-513.

9. Gerbershagen HJ, Rothaug J, Kalkman CJ, Meissner W. Determination of moderate-to-severe postoperative pain on the numeric rating scale: a cut-off point analysis applying four different methods. Br J Anaesth. 2011;107(4):619-626.

10. Fredheim OM, Borchgrevink PC, Kvarstein G. [Post-operative pain management in hospitals]. Tidsskr Nor Laegeforen. 2011;131(18): 1772-1776. Norwegian.
11. Breivik H, Borchgrevink PC, Allen SM, et al. Assessment of pain. Br J Anaesth. 2008;101(1):17-24.

12. Backryd E, Larsson B. Movement-evoked breakthrough cancer pain despite intrathecal analgesia: a prospective series. Acta Anaesthesiol Scand. 2011;55(9):1139-1146.

13. Motamed C, Farhat F, Remerand F, Stephanazzi J, Laplanche A, Jayr C. An analysis of postoperative epidural analgesia failure by computed tomography epidurography. Anesth Analg. 2006;103(4): 1026-1032.

14. Hermanides J, Hollmann MW, Stevens MF, Lirk P. Failed epidural: causes and management. Br J Anaesth. 2012;109(2):144-154.

15. Hamilton CL, Riley ET, Cohen SE. Changes in the position of epidural catheters associated with patient movement. Anesthesiology. 1997;86(4):778-784.

16. Souvatzis X, Diamantaki E, Korda D, Dermitzakis E, Zaganas I, Tzanakis NE. Predictors of laterality of motor block during epidural analgesia in a mixed surgical population. Acta Anaesthesiol Scand. 2013;57(1):126-132.

17. Afshan G, Chohan U, Khan FA, Chaudhry N, Khan ZE, Khan AA. Appropriate length of epidural catheter in the epidural space for postoperative analgesia: evaluation by epidurography. Anaesthesia. 2011; 66(10):913-918

18. Konigsrainer I, Bredanger S, Drewel-Frohnmeyer R, et al. Audit of motor weakness and premature catheter dislodgement after epidural analgesia in major abdominal surgery. Anaesthesia. 2009;64(1):27-31.

19. Donatelli F, Tran D, Mistraletti G, Carli F. Epidural analgesia in the Post-anaesthesia Care Unit. Curr Drug Targets. 2005;6(7):795-806.

20. Curatolo M, Kaufmann R, Petersen-Felix S, Arendt-Nielsen L, Scaramozzino P, Zbinden AM. Block of pinprick and cold sensation poorly correlate with relief of postoperative pain during epidural analgesia. Clin J Pain. 1999;15(1):6-12.

21. Breivik H, Stubhaug A. Management of acute postoperative pain: still a long way to go! Pain. 2008;137(2):233-234.
Local and Regional Anesthesia

\section{Publish your work in this journal}

Local and Regional Anesthesia is an international, peer-reviewed, open access journal publishing on the development, pharmacology, delivery and targeting and clinical use of local and regional anesthetics and analgesics. The journal welcomes submitted papers covering original research, basic science, clinical studies, reviews \& evaluations,

\section{Dovepress}

guidelines, expert opinion and commentary, case reports and extended reports. The manuscript management system is completely online and includes a very quick and fair peer-review system, which is all easy to use. Visit http://www.dovepress.com/testimonials.php to read real quotes from published authors. 